\title{
Cryptosporidium parvum Antigen Measurement
}

National Cancer Institute

\section{Source}

National Cancer Institute. Cryptosporidium parvum Antigen Measurement. NCI

Thesaurus. Code C154831.

The determination of the Cryptosporidium parvum antigen present in a sample. 